Res., Soc. Dev. 2019; 8(4):e1284950

ISSN 2525-3409 | DOI: http://dx.doi.org/10.33448/rsd-v8i4.950

\title{
Matemática, Software e YouTube: Possibilidades para professores e alunos em sala de aula
}

Mathematics, Software and YouTube: Possibilities for teachers and students in the classroom

Matemáticas, Software y YouTube: Posibilidades para profesores y alumnos en el aula

\author{
Alvaro Júnio Bertipaglia da Silva \\ ORCID: https://orcid.org/0000-0002-8151-5078 \\ Universidade Federal de Mato Grosso, Brasil \\ E-mail: alvarojuniosilva@gmail.com \\ Ana Graciela Mendes Fernandes da Fonseca Voltolini \\ ORCID: https://orcid.org/0000-0002-5918-5113 \\ Universidade de Cuiabá, Brasil \\ E-mail: fonsecaanagraciela@gmail.com
}

Recebido: 23/01/2019 | Revisado: 30/01/2019 | Aceito: 07/02/2019 | Publicado: 13/02/2019

\section{Resumo}

Os alunos tem familiaridade e contam com fácil acesso a smartphones, tablets, computadores e aplicativos e gostam de utilizá-los. Assim, o objetivo desse artigo é apresentar uma proposta de aula que utiliza tecnologias digitais e seus recursos para o processo de ensinoaprendizagem na disciplina de matemática. Trata-se de um artigo de revisão bibliográfica. Desta forma, a partir da revisão: identificamos os desafios e potencialidades das Tecnologias Digitais de Informação e Comunicação - TDIC aplicadas a Educação; apontamos as principais dificuldades no ensino-aprendizagem do conteúdo "gráfico de função do segundo grau" e sugerimos um plano de aula para o ensino deste conteúdo nas aulas de matemática utilizando dois recursos: o software GeoGebra e vídeos no YouTube. A literatura e as potencialidades e características dos recursos sugeridos demonstram como a proposta pode contribuir para melhor compreensão do conteúdo, por exemplo, na visualização pelo aluno do gráfico de função. Deste modo, consideramos que a proposta apresentada favorece o processo de ensino-aprendizagem.

Palavras-chave: TDIC; Matemática; Gráfico de função. 


\section{Abstract}

Students are familiar and have easy access to smartphones, tablets, computers and applications and enjoy using them. Thus, the purpose of this article is to present a lesson proposal that uses digital technologies and its resources for the teaching-learning process in the mathematics discipline. This is a bibliographical review article. Thus, from the review: we identify the challenges and potentialities of Digital Information and Communication Technologies - TDIC applied to Education; we pointed out the main difficulties in teachinglearning "second degree function graph" content and suggested a lesson plan for teaching this content in math classes using two resources: GeoGebra software and videos on YouTube. The literature and the potentialities and characteristics of the suggested resources demonstrate how the proposal can contribute to a better understanding of the content, for example, in the student's visualization of the function graph. Thus, we consider that the proposal presented favors the teaching-learning process.

Keywords: TDIC; Mathematics; Function graph.

\section{Resumen}

Los alumnos tienen familiaridad y cuentan con fácil acceso a smartphones, tabletas, computadoras y aplicaciones y les gusta usarlos. Así, el objetivo de este artículo es presentar una propuesta de clase que utiliza tecnologías digitales y sus recursos para el proceso de enseñanza-aprendizaje en la disciplina de matemáticas. Se trata de un artículo de revisión bibliográfica. De esta forma, a partir de la revisión: identificamos los desafíos y potencialidades de las Tecnologías Digitales de Información y Comunicación - TDIC aplicadas a la Educación; apuntamos a las principales dificultades en la enseñanza-aprendizaje del contenido "gráfico de función del segundo grado" y sugerimos un plan de clase para la enseñanza de este contenido en las clases de matemáticas utilizando dos recursos: el software GeoGebra y vídeos en YouTube. La literatura y las potencialidades y características de los recursos sugeridos demuestran cómo la propuesta puede contribuir a una mejor comprensión del contenido, por ejemplo, en la visualización por el alumno del gráfico de función. De este modo, consideramos que la propuesta presentada favorece el proceso de enseñanzaaprendizaje.

Palabras clave: TDIC; matemáticas; Gráfico de función. 


\section{Introdução}

Com a popularização das tecnologias digitais de informação e comunicação (TDIC) a sociedade tornou-se cada vez mais conectada, além de implicar na reconfiguração de processos, hábitos e atividades. A partir desse cenário, o contexto escolar também vem sendo impactado: alunos chegam à escola de posse de celulares e smartphones e boa parte dos professores não alfabetizados digitalmente, buscam compreender e como tirar partido dessa "nova" realidade. Cabe aos professores aproveitar esses recursos digitais também para o processo de ensino-aprendizagem (Gabriel, 2013).

Dentro do universo das mídias digitais, temos uma gama de recursos que podem enriquecer a aula e aproximar o professor desta realidade e linguagem mais comum aos alunos. Além disso, o uso desses recursos pode facilitar a compreensão do aluno e não restringir a aula a lousa e ao formato expositivo. É importante salientar que recursos digitais não podem ser utilizados de forma desconexa aos conteúdos e realidade dos alunos e da escola. Partimos de um conceito de mídia digital como um meio para facilitar o acesso e construção do conhecimento, ou seja, deve ter um objetivo previamente esquematizado e que justifique o uso. Utilizar as mídias digitais em sala de aula exige trabalho, dedicação e planejamento.

O ensino da matemática apresenta desafios, principalmente diante dos índices no Brasil ${ }^{1}$, em que os alunos têm nível insuficiente de aprendizado nesta disciplina. Em números, apenas $7,3 \%$ dos alunos brasileiros do $3^{\circ}$ ano do ensino médio têm aprendizado adequado em matemática, segundo relatório do Movimento Todos Pela Educação (2017)². É comum os alunos apresentarem dificuldades em aprender conceitos elementares. Entre os motivos podem estar: o desinteresse pela matemática em virtude da falta de proximidade com o conteúdo e a linguagem empregada pelo professor. Os dados do Sistema de Avaliação da Educação Básica (Saeb) de 2017 divulgados pelo Ministério da Educação (MEC) revelam que no ensino médio a maioria dos estudantes não é capaz de resolver problemas com operações fundamentais com números naturais ou reconhecer o gráfico de função a partir de valores fornecidos em um texto.

\footnotetext{
${ }^{1} 7$ de cada 10 alunos do ensino médio têm nível insuficiente em português e matemática, diz MEC. Disponível em: https://g1.globo.com/educacao/noticia/2018/08/30/7-de-cada-10-alunos-do-ensino-medio-tem-nivelinsuficiente-em-portugues-e-matematica-diz-mec.ghtml.

${ }^{2}$ Pesquisa aponta retrocesso no aprendizado do ensino médio brasileiro. Disponível em: https://oglobo.globo.com/sociedade/educacao/pesquisa-aponta-retrocesso-no-aprendizado-do-ensino-mediobrasileiro-20788792.
} 
Considerando o cenário exposto, o objetivo é apresentar uma proposta de aula que utiliza tecnologias digitais e seus recursos para o processo de ensino-aprendizagem de matemática. Exploramos meios possíveis e interessantes para o aluno, que conecta a atividade ao seu contexto, bem como o aperfeiçoamento da prática pedagógica do professor a partir de novas ferramentas e experiências. Para isso, propomos o ensino do gráfico de função do segundo grau, ou função quadrática, com o uso de um canal no YouTube e do software GeoGebra.

\section{Métodos}

O presente artigo foi elaborado a partir de pesquisa bibliográfica e a sistematização de situações específicas para o ensino de funções do segundo grau através de mídias digitais, a partir da vivência e experiência no ensino da matemática e necessidades dos alunos na aprendizagem deste conteúdo. Com base neste referencial, apresentamos uma proposta que integre dois recursos digitais, o software GeoGebra e um canal no YouTube, com a aula expositiva do professor.

A pesquisa tem abordagem qualitativa, segundo Bogdan e Biklen (1994) a pesquisa qualitativa envolve a obtenção de dados descritivos obtidos no contato direto do pesquisador com a situação estudada e enfatiza mais o processo do que o produto.

Para Lüdke e André (2013) a investigação qualitativa deve apresentar cinco características básicas, ou algumas delas para caracterizar essa abordagem metodológica. São elas:

1 - a pesquisa qualitativa tem o ambiente natural como sua fonte direta de dados e o seu pesquisador como seu principal instrumento; 2 - os dados coletados são predominantemente descritivos; 3 - a preocupação com o processo é muito maior com o produto; 4 - o significado que as pessoas dão as coisas e à sua vida são focos de atenção especial do pesquisador; 5 - a análise dos dados tende a seguir um processo indutivo (Lüdke; André, 2013, p. 12).

Dessa forma, compreendemos que se trata de pesquisa qualitativa, pois, o pesquisador esteve à frente de todo o processo de coleta e sistematização das informações a partir de sua prática docente. Os dados apresentados são descritivos e buscam apresentar uma atividade para a sala de aula para o ensino de matemática.

\section{Mídias digitais: possibilidades e desafios}

Com a difusão das novas tecnologias de informação e comunicação, o papel do professor vem sendo questionado, redefinido. De detentor do saber e conhecimento para a 
Res., Soc. Dev. 2019; 8(4):e1284950

ISSN 2525-3409 | DOI: http://dx.doi.org/10.33448/rsd-v8i4.950

mediação, é inevitável destacar a descentralização da informação, com o acesso cada vez mais facilitado pela internet e dispositivos digitais, especialmente as tecnologias móveis. Sem contar, a familiaridade destas tecnologias extremamente presentes no cotidiano, não sendo diferente com os alunos e a escola.

Nesse sentido, por que não utilizar as mídias digitais como aliada do professor? Poderia facilitar a compreensão do aluno, melhorar a didática do docente e tornar a aula mais atraente e prazerosa para os estudantes. Segundo Bezerra, na educação o termo mídia "passa a ter um significado mais amplo, designa qualquer meio ou ferramenta de tecnologia da informação e comunicação que é utilizada no ensino e formação dos alunos" (Bezerra, 2017, p. 3).

As mídias digitais podem ser de grande utilidade no contexto escolar. Por meio delas, os professores podem melhorar a compreensão dos conteúdos por parte de seus alunos, à medida que aproximam da realidade deles. Um dos problemas da compreensão da matemática é que muitas vezes os alunos não entendem a linguagem empregada pelos professores em suas aulas. Tais empecilhos poderiam ser contornados com a utilização de recursos midiáticos no processo de ensino. Contudo, alerta Miranda:

O problema reside em que alguns professores têm uma concepção romântica sobre os processos que determinam a aprendizagem e a construção de conhecimento e concomitantemente do uso das tecnologias no ato de ensinar e aprender. Pensam que é suficiente colocar os computadores com algum software ligados à Internet nas salas de aula que os alunos vão aprender e as práticas se vão alterar. Sabemos que não é assim. [...] Os efeitos positivos só se verificam quando os professores acreditam e se empenham de "corpo e alma" na sua aprendizagem e domínio e desenvolvem atividades desafiadoras e criativas, que explorem ao máximo as possibilidades oferecidas pelas tecnologias (2007, p. 44).

Tratar as mídias digitais como uma forma de entretenimento aos alunos ou simplesmente para descontrair o ambiente não significa utilizar a tecnologia de maneira que impacte no ensino. Inserir as mídias digitais na sala de aula requer trabalho e empenho dos docentes, bem como aproximar o contexto da aula com a mídia que está sendo empregada. Para Lévy:

As novas tecnologias da comunicação e da informação transformam o conceito de conhecimento. O adquirir de competências torna-se um processo contínuo e múltiplo, em suas fontes, em suas vias de acesso, em suas formas. Um autêntico universo oceânico de informações alimenta o fluxo incessante de construções possíveis de novos saberes (2008, p. 161). 
Os alunos podem construir seu conhecimento juntamente com as mídias digitais que já fazem parte de suas vidas, mas que não são exploradas, sujeitas apenas ao entretenimento. Incrementá-las junto ao processo de ensino-aprendizagem significa defender a ideia de que o conhecimento pode ser construído transversalmente.

O professor não pode ter medo das mídias digitais. É necessário desconstruir esse conceito. Muitos se sentem inseguros em utilizá-las por medo de errar perante seus alunos ou perder espaço, como detentor do saber. A respeito deste fato, D’Ambrosio discorre:

\footnotetext{
Não há dúvida quanto à importância do professor no processo educativo. Fala-se e propõe-se tanto educação a distância quanto outras utilizações de tecnologia na educação, mas nada substitui o professor. Todos esses serão meios auxiliares para o professor. Mas o professor, incapaz de utilizar desses meios, não terá espaço na educação. $O$ professor que insistir no seu papel de fonte e transmissor de conhecimento está fadado a ser dispensado pelos alunos, pela escola e pela sociedade em geral (2008, p. 79).
}

O professor precisa compreender que sempre terá o seu papel, afinal nessa concepção de ensino, defendemos a mediação do docente. O professor deve utilizar as TDIC como apoio para facilitar a compreensão dos conteúdos, mas o mediador do processo deve ser o professor.

De acordo com Ponte e Serrazina, para que o professor saiba como trabalhar com as mídias digitais é necessário que ele tenha "o conhecimento de implicações sociais e éticas das TIC; a capacidade de uso de software utilitário; a capacidade de uso e avaliação de software educativo e; a capacidade de uso de TIC em situações de ensino-aprendizagem” (1998, p. 12).

Dessa forma, percebemos que trabalhar com tecnologias digitais em sala de aula exige capacitação e empenho do docente, mas que tais contribuições podem ser extremamente importantes no ensino da matemática. As mídias digitais podem favorecer o desenvolvimento de importantes saberes, bem como aliar junto a isso uma visão mais positiva da matemática, tão assombrada pelo fracasso na concepção dos alunos.

\section{Resultados}

O YouTube é uma plataforma online de compartilhamento de vídeos que permite tanto assistir conteúdo como também criar material em forma de vídeo, seja filmes caseiros, videoclipes, opiniões, curiosidades, tutoriais. Na atualidade, se tornou um fenômeno por sua infinidade de conteúdos.

As pessoas utilizam a plataforma para muitas ocasiões, como para aprender alguma atividade, tirar dúvidas. Se você não sabe fazer determinada receita na cozinha, o YouTube pode ajudar. O site responde com vários vídeos que ensinam como fazer e como otimizar a 
tarefa. Uma figura, um profissional, bastante conhecido neste contexto é o youtuber, que é a pessoa que cria conteúdos para a plataforma, uma espécie de apresentador de TV, que tem um canal e publica os vídeos.

Uma rápida pesquisa na plataforma sobre aprender matemática, resulta em inúmeros canais com youtubers que ensinam os conteúdos de forma bastante irreverente, que muitas vezes o professor em sala de aula tem dificuldades. O youtuber seria uma espécie de professor virtual gratuito em canais de educação.

Um deles, que já acumula mais de um milhão de inscritos é o canal "Matemática Rio com Prof. Rafael Procopio". O professor apresenta inúmeras aulas, adicionadas semanalmente em que ensina matemática. Ao buscar por "Função Quadrática", temos uma lista com doze vídeos no qual o professor ensina a respectiva função, desde os conceitos iniciais aos mais avançados. A respeito do gráfico de construção da parábola, nosso tema estudo, encontramos uma aula de aproximadamente uma hora de duração.

Além do YouTube, no âmbito dos recursos digitais que podem ser utilizados também para o processo de ensino-aprendizagem, temos os softwares, a exemplo do GeoGebra. O GeoGebra é um software de acesso livre que combina conceitos de geometria e de álgebra e é escrito em linguagem Java, o que faz com que ele possa ser instalado em vários dispositivos, como tablets, smartphones e computadores de mesa.

O programa foi criado em 2001 para ser utilizado em sala de aula, permite a construção de pontos, retas, segmentos de reta, inserir funções, fazer cálculos de funções, encontrar raízes e pontos extremos de uma função. Com isso, o programa integra álgebra, cálculo e geometria tudo em um único programa, trabalhando inclusive com questões de geometria em três dimensões.

Na proposta da atividade utilizando este programa, recomendamos que seja utilizado a versão para computadores. Apesar do software estar disponível para celulares, não temos garantia que todos os alunos envolvidos na atividade terão aparelhos compatíveis com o programa. Ao instalar o GeoGebra nos computadores do laboratório de informática, garantimos que nenhum aluno fique de fora da atividade.

Com base no objetivo deste artigo, propor a utilização dos recursos citados acima para o ensino do gráfico de funções do segundo grau, como artifício para melhorar a compreensão por meio de diversos recursos disponíveis, descrevemos abaixo a proposta de uso para aulas de matemática. 
Quadro 1: Proposta de atividades utilizando o YouTube e o software GeoGebra

\section{ATIVIDADE 1}

Para esta abordagem é necessário que os alunos já tenham visto o conceito de Gráfico de Função do $2^{\circ}$ grau na aula tradicional. Nesse sentido, é provável que eles ainda tenham muitas dúvidas para desenvolver a atividade,

visto que ainda não compreenderam com clareza o conceito. Antes de iniciar esta atividade, os alunos irão assistir o vídeo "PARÁBOLA - Roteiro para a construção do gráfico da função do segundo grau" disponível na plataforma YouTube.

\section{Ações e questionamentos}

Criar os controles deslizantes no GeoGebra. Os controles deslizantes no software funcionam como sendo os coeficientes da função do segundo grau. Eles serão criados de uma forma genérica, para que possam ser movimentados com a posterior construção do gráfico.

\section{Questões:}

É possível compreender para que servem os coeficientes na função quadrática de acordo com as ilustrações realizadas pelo professor Procópio? ${ }^{3}$

O que acontecerá caso movermos o controle deslizante a para números negativos? E positivos?

\section{ATIVIDADE 2}

\section{Ações e questionamentos}

Traçar no GeoGebra o gráfico da função quadrática elementar $f(x)=a x^{2}+$ $b x+c$. No controle deslizante $\mathbf{a}$, arrastar para $\mathbf{a}=1$.

Questões:

O que acontece com o gráfico da função ao movimentarmos o coeficiente a apenas para números maiores que zero? Segundo o professor Procópio, o que isso indica?

Faça o mesmo exercício, sempre voltando todos os coeficientes para o zero antes de iniciar o processo. Altere para números positivos o coeficiente $\mathbf{b}$ e $\mathbf{c}$ da função.

\section{ATIVIDADE 3}

Habilidades e competências relacionadas

- Conhecer o exemplo mais comum de função do segundo grau e aprender a reconhecer funções quadráticas por meio de seu gráfico.

- Identificar a função de cada um dos coeficientes da função do segundo grau, o que acontece com o gráfico dela ao movimentar cada um de seus coeficientes.

\section{Ações e questionamentos}

Trace na mesma janela os gráficos de cada par de funções:
a) $x^{2}+2 x$ b) $x-1$
c) $7 x^{2}-2$
d) $x^{2}+8 x+9$
e) $9-x^{2}$
f) $9 x^{3}-x^{2}$

Questões:

Quais dessas funções são função do segundo grau?

Você consegue verificar no vídeo do professor Procópio o motivo pelo qual a forma de escrita da função ser diferente e mesmo assim, ela ser uma função quadrática?
Habilidades e competências relacionadas

- Possibilitar a ideia de que nem sempre a forma como uma função vem escrita significa que ela seja ou não função quadrática.

\section{Fonte: Autores (2018)}

No quadro 1 , descrevemos a atividade a ser desenvolvida na proposta de aula com a utilização dos recursos digitais selecionados. $\mathrm{O}$ intuito é potencializar ainda mais o processo

\footnotetext{
${ }^{3}$ Ao nos referirmos ao professor Procópio, estamos nos referindo ao vídeo intitulado "Parábola - Roteiro para a construção do gráfico da função do segundo grau" disponível na plataforma YouTube: https://www.youtube.com/watch? v=nIPexEaUdM0.
} 
ISSN 2525-3409 | DOI: http://dx.doi.org/10.33448/rsd-v8i4.950

com a utilização das duas mídias, maximizando os resultados. É importante salientar que as atividades podem ser executadas mais de uma vez, com exemplos distintos, até que o professor perceba a real compreensão dos alunos.

Figura 1: Ilustração do software GeoGebra para as atividades propostas

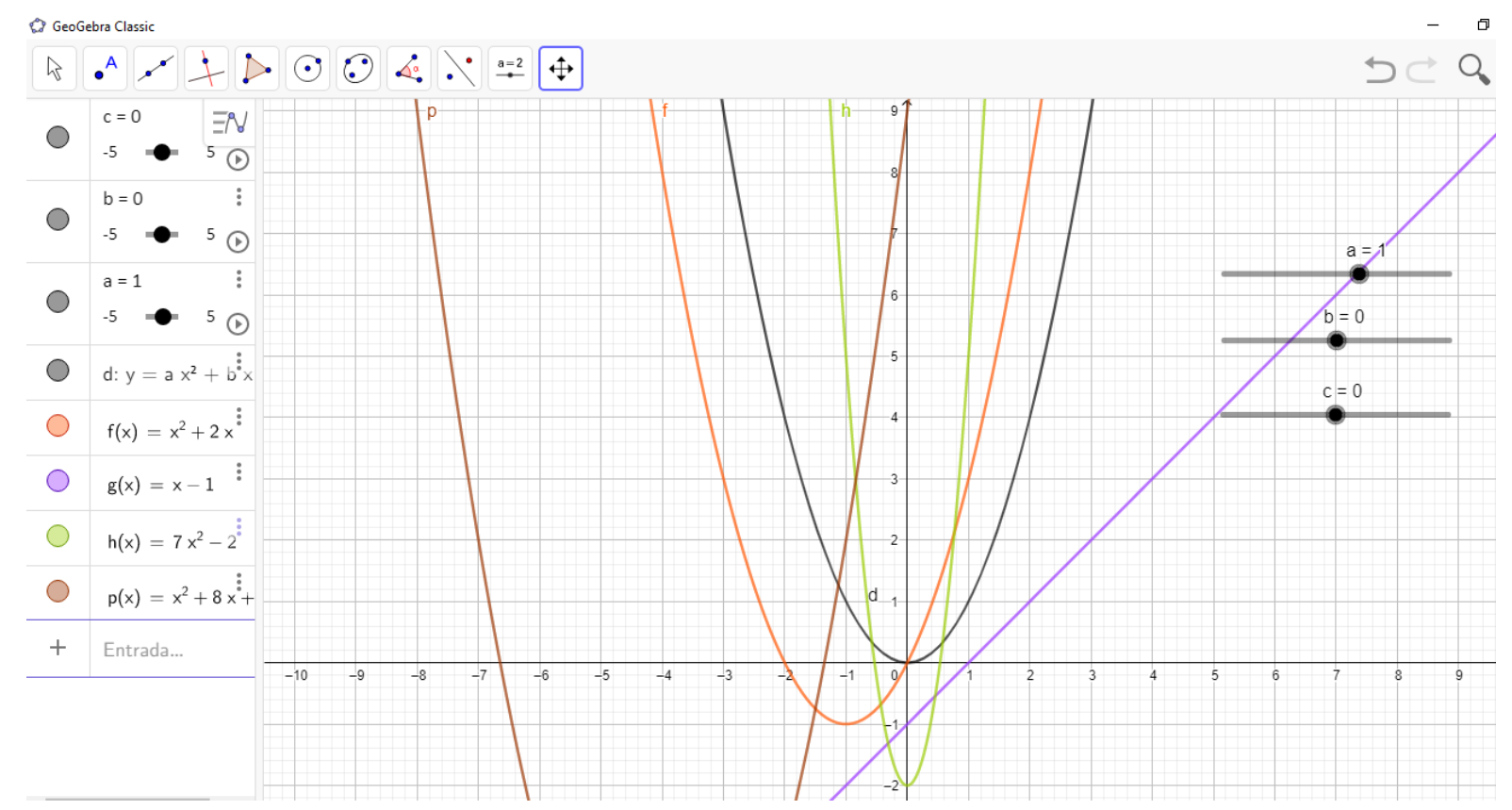

Fonte: Autores (2018)

A figura 1 ilustra como o programa apresenta os gráficos elaborados. Nele, podemos visualizar gráficos de função quadrática e gráficos de função do primeiro grau, onde se espera que os alunos saibam as diferenças entre elas.

\section{Discussão}

A matemática é uma das disciplinas mais temidas pelos alunos durante a vida escolar. Conforme avançam em seus estudos, esta ciência vai se tornando bastante nebulosa para alguns deles. Lins (2012) teoriza que isto ocorre pelo fato dos alunos não conseguirem aplicar a matemática vista na escola no seu cotidiano. Os estudantes acreditam que a matemática é estática, não tem aplicação alguma e é restrita a sala de aula. Logo, como indica Zeichner (2003) e Onuchic \& Allevato (2012), se torna necessária uma educação voltada para uma prática reflexiva, com o intuito de propor ao aluno um aprendizado voltado para a resolução de problemas de seu próprio cotidiano, como uma forma de validar na prática o que estudam na escola.

Nesse sentido, quando a incógnita aparece em seus estudos, fica tudo ainda mais complicado. "Porquê empregar letras onde devem conter apenas números?" - Esse 


\title{
Res., Soc. Dev. 2019; 8(4):e1284950
}

ISSN 2525-3409 | DOI: http://dx.doi.org/10.33448/rsd-v8i4.950

questionamento faz parte da vida do professor que ensina matemática, que escuta de seus alunos rotineiramente. $\mathrm{O}$ grau de dificuldade aumenta no decorrer dos anos, e ao chegar no ensino médio, uma aula que deveria ser um prazer para todos, acaba virando um fardo muito pesado que os alunos não conseguem mais compreender.

As funções, conteúdos que tomam a maior parte do tempo do primeiro ano do ensino médio, podem representar facilmente situações cotidianas através de leis matemáticas. É possível, por exemplo, modelar problemas do preço de um produto do supermercado, ao abastecer o carro no posto de gasolina, o crescimento da massa de um bolo, entre outros. Inúmeras situações do cotidiano poderão ser explicadas por meio delas. As funções podem ser apresentadas através de gráficos para melhor visualização das situações. Nesse sentido:

\begin{abstract}
Os gráficos apresentam uma importância muito grande para o aprendizado da matemática, uma vez que eles são a fotografia da compreensão e do entendimento da solução de um problema matemático e na, maioria das vezes, é essa solução geométrica que nos permite apresentar a solução do problema de forma analítica. É tão importante que é usado com frequência como recurso didático para o ensino da matemática, pela visão de conjunto e rapidez do problema. A representação gráfica [...] de uma função matemática ou simplesmente de uma situação matemática fornece uma visão de conjunto mais rápida do que a observação direta dos dados numéricos (Oliveira, 2006, p. 10).
\end{abstract}

Sendo assim, os gráficos atuam no sentido de ilustrar as informações de que tratam uma função. Entretanto, os alunos apresentam inúmeras dificuldades quando o assunto é traçar tais gráficos. De acordo com Oliveira:

Entre tais dificuldades, podemos citar: marcar pontos no plano cartesiano, operar com números inteiros e racionais, determinar domínio e imagem. Além disso, os alunos apresentam grandes dificuldades em traçar gráfico de uma função definida por mais de uma sentença. Quando se trata de funções trigonométricas, às dificuldades já citadas se sobrepõem as relacionadas ao cálculo do valor da função num ponto, fazer a diferença entre graus e radianos, encontrar domínio, imagem e período (2006, p. 12).

Dessa forma, percebemos que as dificuldades para aprender a construir o gráfico de uma função são muitas, que faz com que o aluno não consiga compreender a essência do conteúdo, ficando perdido em meio a tantas informações. Assim, acreditamos que uma atenção especial deve ser dada para que o aluno aprenda de fato.

Borba \& Penteado (2001) indicam o quanto ainda é expressiva a reprovação dos alunos em Matemática. Sendo assim, os autores relatam que no nível superior, desenvolveram um experimento para ensinar matemática por meio de softwares educacionais. Nesses softwares, é possível desenvolver o aprendizado por meio da experimentação: cada aluno é 
autor de seu processo de construção do conhecimento. Ao fazer as experiências nos softwares, podem chegar a descobertas que passam despercebidas na aula expositiva. Os autores indicam que houve uma melhoria na compreensão com o incremento desses recursos e de situações que fizessem sentido ao aluno.

Ao construir o conceito a respeito de funções apenas por meio de tabelas que associam a y um elemento x do domínio, os alunos ficam limitados. Essas tabelas geralmente trabalham com valores próximos a zero, tanto positivo quanto negativo, o que faz com que eles não consigam aprofundar ou generalizar a forma do gráfico.

Outro obstáculo a ser superado, é a forma pela qual os livros didáticos apresentam os conteúdos. Segundo Oliveira:

\begin{abstract}
Sobre os obstáculos didáticos, os mesmos são considerados como aqueles que apresentam os resultados das estratégias de ensino propostas. Muitos livros didáticos, por exemplo, apresentam primeiro as funções na sua forma algébrica e depois o seu gráfico, sem fazer o caminho inverso constituindo assim um obstáculo didático para resolução de problemas que partem da situação inversa, ou seja, do quadro geométrico para o algébrico (2006, p. 29).
\end{abstract}

Por exemplo, no livro didático Matemática: Ciência e aplicações: ensino médio, volume 1 (Iezzi et. al. 2016), ao introduzir o conteúdo função quadrática, o material faz da seguinte forma:

\begin{abstract}
Situação 1: Um campeonato de futebol vai ser disputado por 10 clubes pelo sistema em que todos jogam contra todos em dois turnos. Quantos jogos serão realizados no campeonato? Contamos o número de jogos que cada clube fará "em casa", ou seja, no seu campo: 9 jogos. Como são 10 clubes, o total de jogos será $10.9=90$. Se o campeonato fosse disputado por 20 clubes [...], poderíamos calcular quantos jogos seriam realizados usando o mesmo raciocínio: $20.19=380$. Enfim, para cada número (x) de clubes, é possível calcular o número (y) de jogos do campeonato. O valor de $\mathrm{y}$ é função de $\mathrm{x}$. Nesse caso, a regra que permite calcular $\mathrm{y}$ a partir de $\mathrm{x}$ é a seguinte: $\mathrm{y}=\mathrm{x}$. $(\mathrm{x}-1)$, ou seja, $\mathrm{y}=x^{2}-x$. Esse é um exemplo de função polinomial do $2^{\circ}$ grau ou função quadrática (Iezzi et. al. 2016, p. 94).
\end{abstract}

Com o exemplo citado, podemos verificar a falta de diálogo que existe entre os conteúdos no próprio livro didático. Ao trabalhar o conceito de função quadrática, o livro poderia explorar a importância do gráfico para que o aluno compreenda mais facilmente. $\mathrm{O}$ gráfico aparece posteriormente, como se não houvesse relação com os exemplos anteriormente explorados. Como primeiro contato, os autores já exploram uma forma algébrica de trabalhar a definição da função.

Nesse sentido, a fragmentação no estudo das funções também é um problema bem grande. Nos livros didáticos, é dedicado cada capítulo para o estudo de um tipo de função. $\mathrm{O}$ empecilho reside no fato de que os autores não fazem uma relação entre os capítulos. Cada 
tipo de função é depositado na sua "caixa" específica, sem relação alguma com as outras. No momento em que é proposto ao aluno um problema que envolve mais de uma função, este não compreende e acaba não tendo êxito em respondê-lo.

$\mathrm{O}$ atual momento do processo de ensino-aprendizagem permite que o conhecimento seja produzido e acessado de diferentes formas, com alternativas que podem facilitar a compreensão dos diversos conteúdos curriculares. As mídias digitais permitem interagir a coleta, a mobilização, a interpretação e a sistematização dos dados. Como afirma Lévy, as multimídias digitais privilegiam uma prática exploratória:

É bem conhecido o papel fundamental do envolvimento pessoal do aluno no processo de aprendizagem. Quanto mais ativamente uma pessoa participar da aquisição de um conhecimento, mais ela irá integrar e reter aquilo que aprender. Ora, a multimídia interativa, graças à sua dimensão reticular ou não linear, favorece uma atitude exploratória, ou mesmo lúdica, face ao material a ser assimilado. É, portanto, um instrumento bem adaptado a uma pedagogia ativa (2008, p. 40).

Essa prática exploratória é privilegiada no momento que o aluno pode ousar. Ao trabalhar com funções em softwares matemáticos, ele pode traçar possibilidades, testar métodos, verificar o que acontece no gráfico das funções quando altera os coeficientes da mesma, estratégias que se fossem realizadas no papel, não permitiriam a versatilidade e otimização proporcionada por softwares como o GeoGebra ou do apoio audiovisual das vídeo-aulas no YouTube.

Essa prática exploratória é privilegiada no momento que o aluno pode ousar. Ao trabalhar com funções em softwares matemáticos, ele pode traçar possibilidades, testar métodos, verificar o que acontece no gráfico das funções quando altera os coeficientes da mesma, estratégias que se fossem realizadas no papel, não permitiriam a versatilidade e otimização proporcionada por softwares como o GeoGebra ou do apoio audiovisual das vídeo-aulas no YouTube.

\section{Considerações finais}

Este artigo exercitou o conteúdo ministrado na Especialização em Mídias Digitais para a Educação, realizado pela Universidade Federal de Mato Grosso e Universidade Aberta do Brasil. Realizamos uma reflexão que exercitasse as habilidades desenvolvidas ao longo do curso, no que compreende ao planejamento e uso de mídias digitais para a educação. Para isso, elaboramos uma proposta de aula que utiliza tecnologias digitais e seus recursos para o processo de ensino-aprendizagem na disciplina de matemática. 
ISSN 2525-3409 | DOI: http://dx.doi.org/10.33448/rsd-v8i4.950

As mídias são inúmeras, meios para se propor uma atividade diferente do ensino tradicional, que proporcione novas visões e suporte para o aluno. Para desenvolver tal atividade, é necessário amplo trabalho na sistematização para que se tenha coerência de modo que faça sentido para os estudantes, proporcionando uma aprendizagem significativa.

Assim, apresentamos um modelo de aula conforme aprendemos durante o curso: juntamos uma mídia digital vídeo (YouTube) e outra software (GeoGebra) para o desenvolvimento de uma aula que utilize das mídias digitais para o ensino de matemática.

Com o vídeo de um canal no YouTube buscamos aproximar a aula da vida do aluno. Os estudantes consomem muito vídeos dessa plataforma. Integrá-la ao processo de ensinoaprendizagem pode aproximá-lo, que ao ter familiaridade com a linguagem, ficam mais entusiasmados com a tarefa proposta.

O potencial do software Geogebra é grande para trabalhar o ensino de gráficos, pois são claros, sem imperfeições, facilitando a visualização do conteúdo para o aluno. Fica implícito que para que o programa seja utilizado de maneira efetiva, existe a necessidade da atividade ser bem planejada.

Dessa maneira, o artigo apresentou ferramentas digitais para uma aula que busca facilitar a compreensão dos alunos na aprendizagem da função quadrática ou do segundo grau, especificamente no comportamento do gráfico ao mover os coeficientes angulares e lineares, verificando o quanto essa ferramenta pode ser um agente facilitador no processo de ensino-aprendizagem.

O plano apresentado abre caminhos para discussões e incentivo para outras iniciativas utilizando mídias digitais para o ensino-aprendizagem de matemática, colaborando no processo de inserção das TDIC na sala de aula.

\section{Referências}

Bezerra, Diogo Henrique. Mídias digitais na Educação. Universidade Federal de mato Grosso: Secretaria de Tecnologia Educacional. Fascículo do curso de Especialização em Mídias Digitais para a Educação: Cuiabá, 2017.

Bogdan, Roberto; Biklen, Sari. Investigação Qualitativa em Educação. Tradutores: Maria João Alvarez, Sara dos Santos e Telmo Batista. Porto - Portugal: Porto Editora, 1994.

Borba, Marcelo de Carvalho; Penteado, Miriam Godoy. Informática e Educação matemática. $2^{\text {a }}$ Ed. Belo Horizonte: Autêntica, 2001.

Carneiro, Vera Clotilde. Funções elementares: 100 situações-problema de matemática. Porto Alegre: Ed. Universidade, 1993. 
ISSN 2525-3409 | DOI: http://dx.doi.org/10.33448/rsd-v8i4.950

D’Ambrosio, Ubiratan. Educação matemática da teoria à prática. 16.ed. Campinas/SP: Papirus, 2008.

Gabriel, M. Educar: a revolução digital na educação. São Paulo: Saraiva, 2013.

Iezzi, Gelson [et. al]. Matemática: ciência e aplicações: ensino médio. V. 01, 9a ed. São Paulo: Saraiva, 2016.

Lévy, Pierre. As Tecnologias da Inteligência: O futuro do Pensamento na Era da Informática. Rio de Janeiro: Ed. 34, 2008.

Lins, Romulo Campos. Matemática, monstros, significados e Educação Matemática. In: Bicudo, Maria Aparecida Viggiani; Borba, Marcelo de Carvalho (org.). Educação Matemática: pesquisa em movimento. $4^{\text {a }}$ Ed. São Paulo: Cortez, 2012. p. 101-131.

Lüdke, Menga; André, Marli. Pesquisa em Educação: abordagens qualitativas. $2^{\text {a }}$ Ed. Rio de Janeiro: EPU, 2013.

Miranda, Guilhermina Lobato. Limites e possibilidades das TIC na educação. Sísifo. Revista de Ciências da Educação, v. 3, p. 41-50, 2007.

Oliveira, Francisco Canindé. Dificuldades na construção de gráficos de funções. Dissertação (Mestrado em Ensino de Ciências Naturais e Matemática) - Universidade Federal do Rio Grande do Norte, Natal, 2006.

Onuchic, Lourdes de La Rosa; Allevato, Norma Suely Gomes. Novas reflexões sobre o ensino-aprendizagem de Matemática através da resolução de problemas. In: Bicudo, Maria Aparecida Viggiani; Borba, Marcelo de Carvalho (org.). Educação Matemática: pesquisa em movimento. $4^{\mathrm{a}}$ Ed. São Paulo: Cortez, 2012. p. 232-252.

Ponte, João Pedro; Serrazina, Lurdes. As novas tecnologias na formação inicial de professores. Lisboa: DAPP do ME, 1998.

Zeichner, Kenneth. Formando professores reflexivos para a educação centrada no aluno: possibilidades e contradições. In: Barbosa, Raquel Lazzari Leite (org.). Formação de educadores: desafio e perspectivas. São Paulo: Editora UNESP, 2003. p. 35-55.

\section{Porcentagem de contribuição de cada autor no manuscrito}

Alvaro Júnio Bertipaglia da Silva - 50\%

Ana Graciela Mendes Fernandes da Fonseca Voltolini - 50\% 